\title{
Chapter \#23
}

\section{EXAMINING HOW POSITIVE AND NEGATIVE EMOTIONS INFLUENCE COGNITIVE PERFORMANCE IN SECONDARY SCHOOLS}

\author{
Sonya Yakimova, Célia Maintenant, \& Anne Taillandier-Schmitt \\ Psychologie des âges de la vie et Adaptation (PAVeA) - EA 2114, Université de Tours, France
}

\begin{abstract}
Few studies have examined the impact of emotions on cognitive (not only academic) performance among adolescents and this is the objective of our research. After ethic committee agreement and parents' authorization, we asked 158 adolescents in secondary schools to respond to the French version of Differential Emotion Scale adapted for school context and to nineteen syllogisms which evaluated cognitive nonacademic performances. As results, we expected that negative emotions related to academic achievement would reduce performance in reasoning and positive emotions would improve it. Our hypotheses were partially validated. The impacts of the results as well as perspectives of future researches in relation with self-esteem, psychological disengagement, dropping out of school were discussed.
\end{abstract}

Keywords: emotions, cognitive performance, deductive reasoning, early- and mid-adolescence, secondary school.

\section{INTRODUCTION}

How emotions could play on cognitive performance in secondary schools? It is still too little known about their influence on cognitive performances at the crucial period of early- and mid-adolescence when many psychological and physical changes take place in a short time (Braconnier \& Marcelli, 1998). In the literature concerning the adults, the results can be contradictory and contingent upon the perceived specific emotion. The affective state is however likely to influence cognitive performances (Blanchette \& Richards, 2010; Oaksford, Morris, Grainger, \& Williams, 1996; Tricard, Maintenant, \& Pennequin, 2018).

\subsection{Age and cognitive performances}

The transition from childhood to adulthood is marked by an increasing in cognitive performances in many domains (Roalf et al., 2014). In the study of age change in cognition the most commonly studied cognitive processes are various forms of reasoning (Byrnes, 2008). Reasoning skills appear early and are developed with advancing age with the exception of elderly people when we observe a progressive decrease in performance in reasoning tasks (De Neys \& Van Gelder, 2009). This improving of performance with age is therefore observed for the different type of reasoning: deductive reasoning (De Neys \& Van Gelder, 2009; Hawkins, Pea, Glick, \& Scribner, 1984), inductive reasoning (Csapó, 1997; Galotti, Komatsu, \& Voelz, 1997) or quantitative reasoning (Chiesi, Gronchi, \& Primi, 2008; Denison, Reed \& Xu, 2013). 
Reasoning performances are often measured by syllogisms, for example, Premise 1: Four legged animals walk / Premise 2: Tigers are four legged animals / Conclusion: Tigers walk. In this example, the conclusion is valid because it follows logically from the premises, and also credible because it is consistent with the established knowledge. The syllogisms reflect mainly the level of deductive reasoning, which corresponds to the use of general laws to draw a conclusion on a particular case (Tricard et al., 2018). The deductive reasoning would be possible from age of 4 years but under certain conditions (Hawkins et al., 1984): when the syllogisms are plausible (valid and credible) rather than imaginary and when there is a correspondence between the formulation and the validity. That is to say when it comes to answering "yes" this syllogism is valid for the syllogisms formulated positively and "no" this syllogism is not valid for the syllogisms formulated negatively. This correspondence would help young children (4 years old) to succeed without using logical reasoning (Markovits, Schleifer, \& Fortier, 1989). Then, we could situate from age of 9 years the possibility of understanding the difference between valid and invalid conclusion about imaginary syllogisms (Galotti et al., 1997). But we could observe a full understanding of the relationship between the premises and the conclusion at age of 11 years (Markovits et al., 1989). During early adolescence, individuals show marked improvements in deductive reasoning (Steinberg, 2005) and the development of deductive reasoning skills would continue until the age of 17-18 years old.

\subsection{Emotions and cognitive performances}

The cognitive performances are not only improved with age. They may also be influenced by other factors and since many decades emotions are mentioned in particular (e.g. Channon \& Baker, 1994; Oaksford et al., 1996; Melton, 1995; Radenhausen \& Anker, 1988). Huntsinger, Isbell, and Clore (2014) remind that affective feelings have an important feedback and an adaptive function and provide information for many cognitive processing outcomes. Schwarz (2012) underlines that affects could influence our cognitive processing by informing us about our psychological environment: for example, negative affect flags the presence of a problem and positive affect notifies a favorable and safe environment. Blanchette (2006) points out that research on psychopathologies with important affective components showed an effect on reasoning as well as the research on cognition, in positive or in negative mood condition, with non-clinical samples. But in which way exactly negative and positive emotions could influence cognitive performances?

\subsubsection{Deleterious effect of negative emotions}

According to Tricard et al. (2018) the deductive reasoning of young people is influenced by emotions. These researchers examined the influence of inducing joy and sadness emotional states on deductive reasoning performances, measured by syllogisms, of children aged from 9-10 years old. They founded a negative effect of sadness on the scores of correct answers to syllogisms compared to joy. Fartoukh, Chanquoy and Piolat (2014) also examined the effect of a mood induction but on phonological working memory capacity in fourth and fifth graders. Their results showed a decreasing of phonological working memory performances in the case of negative mood induction procedure. Tricard and her colleagues (2018) as well as Fartoukh et al. (2014) specify that a negative affective experience will lead to a poor cognitive performance. Thus, experiencing a negative affective state should weaken the performance of pupils in cognitive tasks like reasoning task. 


\subsubsection{Facilitative effect of positive emotions}

According to Bryan and Bryan (1991) a positive emotional state about school and learning promotes success and speed in solving reasoning problems. They randomly assigned children (third to fifth grades) and students in junior high and high school to a positive-mood induction condition or a no-treatment control condition. The objective was to assess the impact of positive moods on students' feelings of self-efficacy and math performance. The results showed that children in the positive-mood condition completed significantly more problems accurately than children in the no-treatment control condition. They also showed that students (in junior high and high school) in the positive-mood induction condition expressed greater self-efficacy for math than students in the control condition. Thus, feeling positive emotions towards learning and college would encourage better results in logical reasoning on a task. For Caparos and Blanchette (2015) positive emotions would indeed have a facilitating effect during a cognitive task. Giroux, Blanchette and Gosselin (2014) confirm that subjects with the induction of a positive emotional state perform better on a reasoning task with syllogisms. The objective of this study was to explore the influence of music-induced joy and sadness on deductive reasoning. The reasoning performance in a music-induced joy condition was much more higher compared to inducing sadness and the absence of emotional induction.

\subsection{Objectives}

The overall conclusions of all the studies in the "Emotions and cognitive performances" section were that there is a deleterious effect of negative emotions as well as a facilitative effect of positive emotions on cognitive performances. These studies were also done with a public of adults or young children. However, few studies have concretely examined the influence of affective state on cognitive and not only academic performance among adolescents. The objective of our research is to bring more information about that topic. As mentioned previously, cognitive performances are influenced by emotions and are improved with age. However, it could exist a differential effect of emotions on cognitive performances. Early adolescents could be more sensitive to emotions because of a poorer development of emotional regulation (Ahmed, Bittencourt-Hewitt, \& Sebastian, 2015). Thus, we also wanted to explore the interaction effect of emotion and age on reasoning at this stage of early- and mid-adolescence which are marked by several changes in a short time.

\subsection{Hypotheses}

As our first hypothesis, we made the assumption that there was a significant correlation and a significant effect of the age on the cognitive performances: the cognitive performances should increase with age (H1). Second, we expected a significant correlation and a significant effect between the emotions about school and the cognitive performances: more the emotions about school are negative the lower should be the cognitive performances $(\mathrm{H} 2 \mathrm{a})$; more the emotions are positive the higher should be the cognitive performances $(\mathrm{H} 2 \mathrm{~b})$. Finally, we expected a significant interaction effect between the age and the emotions about school on the cognitive performances: more the emotions about school are negative and more the age is low the lower should be the cognitive performances (H3a); more the emotions are positive and more the age is high the higher should be the cognitive performances (H3b). All the hypotheses are summarized in Figure 1. 
Figure 1.

Hypotheses.

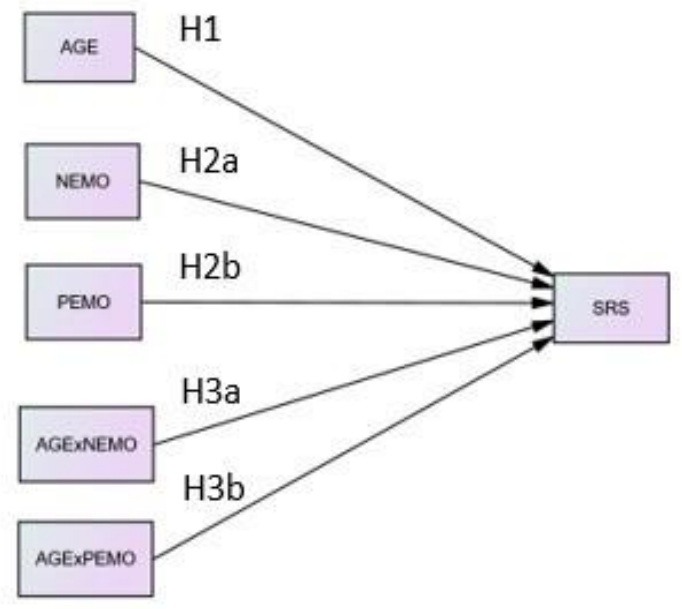

Legend: $N E M O=$ Negative emotions; PEMO = Positive emotions; SRS = Syllogism reasoning score as a measure of Cognitive performances; AGExNEMO = interaction between Age and NEMO; AGEXPEMO = interaction between Age and PEMO.

\section{METHODS}

\subsection{Participants}

158 students in secondary school (83 boys and 75 girls) participated in our research. They were 12 years-old on average $(11-14$ years, $S D=0.78)$. The most of them were in $6^{\text {th }}$ (11-12 years old) and in $5^{\text {th }}$ class (12-13 years old); two participants were in $4^{\text {th }}(13-14$ years old) and two others in 3th class (14-15 years old). 92\% of the participants were French native speakers and the others were speaking French since more than five years. It is important to precise that we did not finish our data collection because of the Covid-19 crisis and we chose to include all the participants that we met. That is why we have only four participants in total for $4^{\text {th }}$ (13-14 years old) and $3^{\text {th }}$ class (14-15 years old).

\subsection{Procedure}

We obtained an ethic committee agreement for our study. We asked first school principals a permission to realize our study in their establishment and then we sent an authorization form to the parents to obtain a permission for the participation of their children. All participants also completed a consent statement and responded to the questionnaires at school, in group.

\subsection{Measures}

Our study contains as measures two questionnaires.

To measure negative (e.g., "Do you have any regrets, do you feel guilty for something that you have done?") and positive emotions (e.g., "Do you feel happy?") related to academic situations, participants completed the 36 items of the French validation of the 
Differential Emotion Scale (DES) proposed by Ricard-St-Aubin, Philippe, Beaulieu-Pelletier and Lecours (2010) adapted firstly to the school context by Galand and Philippot (2005). Items were rated on a 5-point Likert scale ranging from 1 (Rarely or never) to 5 (Very often). The Cronbach's alpha coefficients for both groups of items measuring positive emotion $(\alpha=0.65)$ or negative emotions $(\alpha=0.92)$ were high and so we could construct two composite variables: positives emotions and negative emotions.

To measure cognitive nonacademic performances, we proposed 19 syllogisms, staying in line with previous studies which used this type of measurement rather than others. We counted the total number of right answers for every participant. She or he needed to choose the fine answer between four different propositions of a possible conclusion of every syllogism (example):

"We tell to the aliens: "All printers need ink"

We also say to them: "My pen needs ink"

What conclusion would the aliens have made?

\author{
o My pen is a printer \\ o My pen is not a printer \\ o My pen is a felt \\ o The aliens could not have concluded"
}

Our syllogisms had neutral emotional content and they were pretested about this in Tricard (2018). The emotionality of the experiment's content has an effect on the cognitive performances (Blanchette \& Richards, 2004; Gosselin \& Blanchette, 2018) and that is why we chose to include this type of syllogisms.

\title{
2.4. Statistical analysis
}

We analyzed our data within a Network (see Fonseca-Pedrero, 2018; Hevey, 2018) and SEM approaches framework. The Network analysis allowed us to explore the partial correlations and links between our different variables. The SEM analysis permitted us to test the impact of emotions on cognitive performances. More precisely the later was a path analysis with a maximum likelihood estimation and we applied bias-corrected percentile bootstrap confidence intervals to test the significance of the different effects. In order to assess the fit of the models, the following indices were used: the ratio $\chi^{2} / \mathrm{df}$ (chi-square/degree of freedom), the $\mathrm{p}$ value, the CFI (Comparative Fit Index), the GFI (Goodness-of-Fit Index), the AGFI (Adjusted Goodness-of-Fit Index), the RMSEA (Root Mean Square Error of Approximation) including the associated 90\% confidence interval (CI) and the RMR (Root Mean Square Residual). The fit of a model is considered excellent for a value of the ratio $\chi^{2} / \mathrm{df}$ less than 2 and a non-significant $\mathrm{p}$ value (Kline, 2011), for CFI, GFI and AGFI coefficient values greater than 0.90 (Mokhtarian \& Ory, 2009), for RMSEA values less than 0.07 (MacCallum, Browne \& Sugawara, 1996) and a maximum upper bound of the $90 \%$ CI of 0.10 (Browne \& Cudek, 1993) and for RMR values less than 0.08 (Gana \& Broc, 2018).

Descriptive Statistics and Network analysis were done with JASP software (JASP Team, 2019) and SEM analysis was realized with AMOS software (Arbuckle, 2014). 


\section{RESULTS}

Descriptive statistics and the zero-order correlation matrix are presented in Table 1 and Table 2. The correlation matrix indicated that there were only two significant correlations between the variables of our interest: a positive relation between Positives emotions and Cognitive performances $(r=.22, \mathrm{p}<.01)$ as well as a negative relation between Positives emotions and Age $(r=-.17, \mathrm{p}<.05)$. This was not a surprise then when we integrated our hypotheses in a model to test with SEM analysis and the fit of the model was very poor $\left(\chi^{2} / d f=228 ; \mathrm{p}=0.000 ; C F I=0.343 ; G F I=0.662 ; A G F I=-0.589 ; R M S E A\right.$ $=1.200,90 \%$ CI $[1.142-1.260])$ and the path coefficient weren't significant except the effect of positive emotions on cognitive performance. As a next step in our analysis we put the three variables from the two significant correlations from Table 2 to a network analysis (Figure 2). This time three partial correlations were significant: the relation between Age and Cognitive performances (H1), between Positives emotions and Age, and, between Positives emotions and Cognitive performances (H2b). Age and Cognitive performances were also negatively connected via Positives emotions. Thus we transposed this model in SEM framework by orienting the effects of the variables in accordance with our hypotheses (e.g. a direct effect from Positives emotions and Cognitive performances, etc.). We obtained a good model fit $\left(\chi^{2} / d f=1.247 ; \mathrm{p}=0.274 ; C F I=0.998 ; G F I=0.995\right.$; $A G F I=0.979 ;$ RMSEA $=0.010,90 \%$ CI $[0.000-0.060])$ but the effect of Age on Cognitive performances wasn't significant $(\beta=0.06, \mathrm{p}=.34,95 \% \mathrm{CI}[-0.119-0.251])$. We redid the analysis by omitting this link of the tested model (Figure 3 ) and the fit was very $\operatorname{good}\left(\chi^{2} / d f=0.745 ; \mathrm{p}=0.338 ; C F I=1.00 ; G F I=0.997 ; A G F I=0.981 ; R M S E A=0.000\right.$, $90 \%$ CI $[0.000-0.020])$. The direct effect from Age to Positive emotions was significant and negative $(\beta=-0.17, \mathrm{p}<.05,95 \%$ CI $[-0.308--0.017])$, with $\mathrm{R}^{2}=0.03$ for Positive emotions. The direct effect from Positive emotions to Cognitive performances was significant and positive $(\beta=0.22, \mathrm{p}<.05,95 \% \mathrm{CI}[0.045-0.381])$, with $\mathrm{R}^{2}=0.05$ for Cognitive performances. The indirect effect from Age to Cognitive performances was also significant but negative $(\beta=-0.04, \mathrm{p}<.05,95 \%$ CI $[-0.104--0.003])$.

Table 1.

Descriptive statistics.

\begin{tabular}{|lcccccc|}
\hline & Sexe & Classe & Age & SRS & NEMO & PEMO \\
\hline Mean & & & 11.873 & 8.595 & 2.063 & 3.177 \\
Median & & & 12.000 & 8.000 & 1.963 & 3.194 \\
Std. Deviation & & 0.780 & 2.481 & 0.617 & 0.565 \\
Skewness & 0.102 & -0.813 & 0.552 & 0.578 & 0.749 & -0.038 \\
Kurtosis & -2.015 & 1.742 & -0.243 & 1.570 & 0.631 & 0.117 \\
Shapiro-Wilk & 0.635 & 0.694 & 0.824 & 0.960 & 0.962 & 0.993 \\
P-value of Shapiro-Wilk & $<.001$ & $<.001$ & $<.001$ & $<.001$ & $<.001$ & 0.703 \\
Minimum & & & 11.000 & 3.000 & 1.037 & 1.667 \\
Maximum & & & 14.000 & 18.000 & 4.370 & 4.889 \\
25th percentile & & & 11.000 & 7.000 & 1.593 & 2.889 \\
50th percentile & & 12.000 & 8.000 & 1.963 & 3.194 \\
75th percentile & & 12.000 & 10.000 & 2.426 & 3.556 \\
\hline
\end{tabular}

Legend: $N E M O=$ Negative emotions; PEMO = Positive emotions; SRS = Syllogism reasoning score as a measure of Cognitive performances. 
Table 2.

Correlation matrix.

\begin{tabular}{|ccccccc|}
\hline & Gender & Class & Age & SRS & NEMO & PEMO \\
\hline Gender & - & & & & & \\
Class & $0.209 * *$ & - & & & & \\
Age & $-0.188^{*}$ & $-0.800^{* * *}$ & - & & & \\
SRD & 0.038 & -0.049 & 0.029 & - & & \\
NEMO & 0.122 & -0.085 & 0.084 & -0.035 & - & \\
PEMO & -0.039 & 0.099 & $-0.167 *$ & $0.220 * *$ & 0.068 & - \\
\hline${ }^{*} \mathrm{p}<.05, * * \mathrm{p}<.01, * * * \mathrm{p}<.001$ & & & & \\
\hline
\end{tabular}

Legend: $N E M O=$ Negative emotions; PEMO = Positive emotions; SRS = Syllogism reasoning score as a measure of Cognitive performances.

Figure 2.

Network analysis.

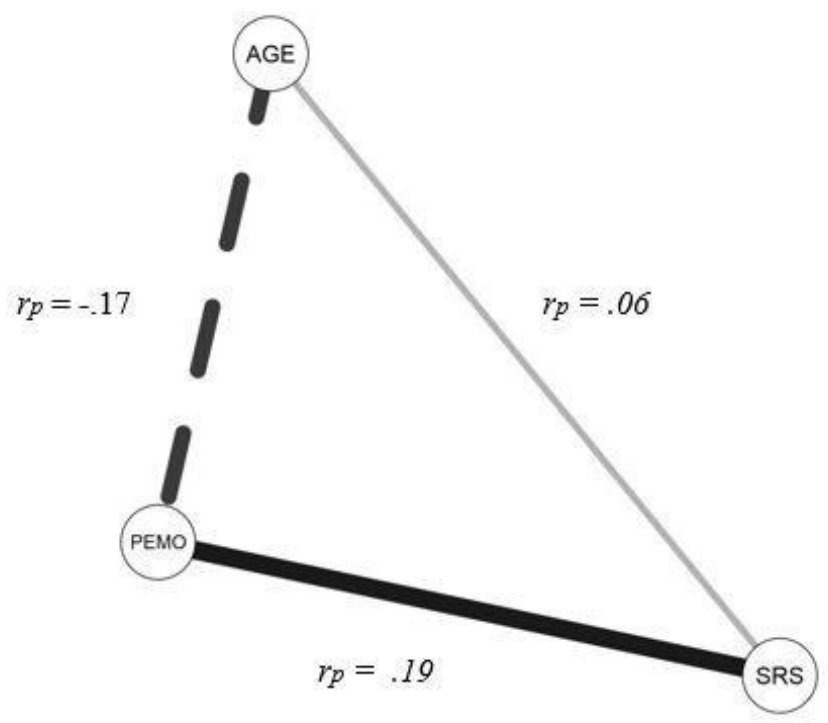

Legend: $N E M O=$ Negative emotions; PEMO = Positive emotions; SRS = Syllogism reasoning score as a measure of Cognitive performances. Solid lines correspond to positive links; dashed lines correspond to negative links. The broader and darker the line, the stronger the link. 
Figure 3.

Path analysis and synthese of the different effects.

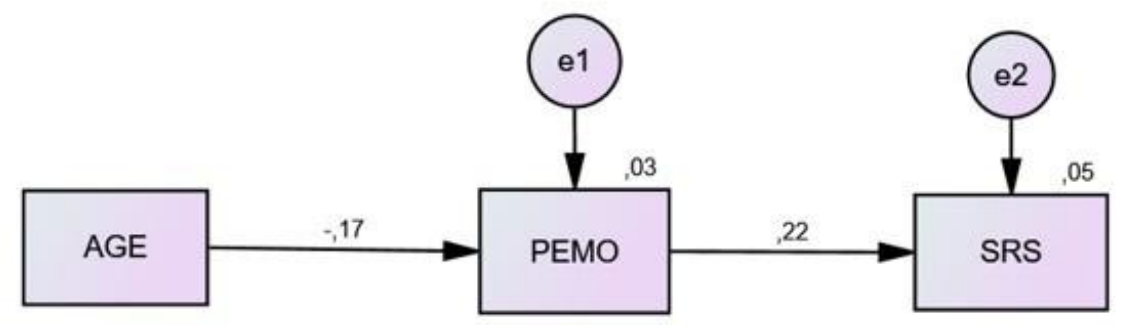

Legend: PEMO = Positive emotions; SRS = Syllogism reasoning score as a measure of Cognitive performances; $e 1=$ residual variance of PEMO; e2 = residual variance of SRS.

\section{DISCUSSION}

Our hypotheses were partially validated. Concerning our first hypothesis, the age didn't directly affect the cognitive performances in our sample. The problem is that the majority of our participants was only 11-12 years old and this is not what we wished. It will be necessary to include more participants who are older (13-14 years old) for the next stage of our research. Thus we can investigate if there is a difference, at least, between the group of 11-12 years old and the group of 13-14 years old pupils. The age had also a partial positive correlation and an indirect negative relation on the cognitive performances via the positive emotions in a network analysis. This negative indirect relation might have a suppression effect on the positive one and may explain why we didn't obtain a significant direct effect. These results give us an insight that the relationship between age and cognitive performance isn't probably unequivocal.

Concerning our second hypothesis, the positive emotions correlated with the performance on the reasoning test but not the negative ones. Consequently, only positive emotions affected the cognitive performance and in connection with our third hypothesis, this is without an interaction with the age of the participants. This is in line with the results of Radenhausen and Anker (1988) and more recently with the results of Caparos and Blanchette (2015) or Wang, Chen, and Yue (2017) where positive emotions improve cognitive performances. This shows that in a learning situation or in a reasoning assessment it is particularly preferable to foster positive emotions, and the later might be encouraged and privileged to facilitate learning and the best possible conditions for pupils' evaluation. What about negative emotions? Some researchers (e.g. Fiedler, 1990; Forgas, 1995; Royce \& Diamond, 1980) explain that reasoning tests are may be less constrained by emotions than other types of tests. It is also possible that pupils entered a state in which feelings do not influence the task performance like the state of flow (Csikszentmihalyi, Abuhamdeh, \& Nakamura, 2005). This could be valuable when both positive and negative emotions don't interfere with cognitive performances but, in our case, there were still a significant relation and a significant influence from positive emotions to cognitive performances. Melton (1995) showed that negative emotions could even improve cognitive performance. 
In our research, we investigated the emotions on a global level as positive and negatives emotions. It will be interesting to study the link and the effect of emotions on cognitive performances on a specific level. May be some specific negative emotions could improve cognitive performances but other could do the opposite. Thus, this might explain why on global level there was no relation and no effect from negative emotions to cognitive performances. May be there is also an explanation in descriptive statistics terms: the mean of negative emotions in our sample is under the theoretical mean of the composite variable. When we explored more in detail the descriptive statistics, $75 \%$ of the participants had a score under this later mean. Which implies that the most of them feels rarely negative emotions about school and thus it is difficult to detect an effect on another variable.

Concerning our third hypothesis, age had a negative indirect effect on cognitive performances mediated by positive emotions. It wasn't in our hypotheses but age had a negative direct effect on positive emotions. These results are in line with these obtained by Galand and Philippot (2005) but on a specific positive emotion level. They founded that reported level of positive emotions decreases with the increase in adolescents'age. Thus decreasing positive emotions would provoke a decreasing in cognitive performances with increasing in age. This statement is opposite on what is generally mentioned in the literature: cognitive performances increase with age (e.g. Brehmer, Li, Müller, von Oertzen, \& Lindenberger, 2007; Cromer, Schembri, Harel, \& Maruff, 2015; Roalf et al., 2014). As we suggested it earlier, the relationship between age and cognitive performance isn't probably unequivocal at this stage of human development. This is important to take in to account about an eventual decreasing in academic performances and dropping out of school in teenage period. Keating (2012) precise that it is possible that factors other than changes in logical structure with age would be implicated in task performance. May be for some pupils in secondary school this phenomenon of decreasing positive emotions is more present than for others and it would be necessary to learn more about it as well as its link with other variables which could interfere with it.

\section{FUTURE RESEARCH DIRECTIONS}

In future research, we must take also in account specific emotions and not only global emotions. We could also explore the influence of emotions on academic performances. Due to the risk of a vicious cycle between psychological disengagement and academic failure, better understanding of the link of emotions about school and academic performance appear like crucial. The understanding of this phenomenon added to the impact of self-esteem (a factor related to cognitive and academic performances, e.g. Simon \& Simon, 1975) on these variables would be important to investigate in order to avoid dropping out of school. It will be also interesting to explore the influence of motivation within a such a theoretical framework. As we know, the motivation is important in school learning (Nicholls $\&$ Thorkildsen, 1995). The perception of the school context by the students have an impact on their motivation (Ryan \& Patrick, 2001) and emotional experience at school (Galand $\&$ Philippot, 2005). Thus, it is plausible that the emotions felt about school and motivation could influence academic performances (e.g. Valiente, Swanson \& Eisenberg, 2012). 


\section{REFERENCES}

Ahmed, S. P., Bittencourt-Hewitt, A., \& Sebastian, C. L. (2015). Neurocognitive bases of emotion regulation development in adolescence. Developmental Cognitive Neuroscience, 15, 11-25. https://doi.org/10.1016/j.den.2015.07.006

Arbuckle, J. L. (2014). IBM SPSS Amos 23 user's guide. IBM, Amos Development Corporation. Retrieved from ftp://public.dhe.ibm.com/software/analytics/spss/documentation/amos/23.0/ en/Manuals/IBM_SPSS_Amos_User_Guide.pdf

Blanchette, I. (2006). The effect of emotion on interpretation and logic in a conditional reasoning task. Memory and Cognition, 34(5), 1112-1125.

Blanchette, I., \& Richards, A. (2004). Reasoning about emotional and neutral materials: Is logic $\begin{array}{llll}\text { affected by emotion? Psychological Science, 15(11), 745-752. } & \text {. }\end{array}$ https://doi.org/10.1111/j.0956-7976.2004.00751.x

Blanchette, I., \& Richards, A. (2010). The Influence of Affect on Higher Level Cognition: A Review of Research on Interpretation, Judgement, Decision Making and Reasoning. Cognition \& Emotion, 24(4), 561-595. https://doi.org/10.1080/02699930903132496

Braconnier, A. \& Marcelli, D. (1998). L'adolescence aux mille visages [The thousand faces of Adolescence]. Ed. Odile Jacob, Paris.

Bryan, T., \& Bryan, J. (1991). Positive Mood and Math Performance. Journal of Learning Disabilities, 24(8), 490-494.

Brehmer, Y., Li, S. C., Müller, V., von Oertzen, T., \& Lindenberger, U. (2007). Memory plasticity across the life span: Uncovering children's latent potential. Developmental Psychology, 43(2), 465-478.

Browne, M. W., \& Cudeck, R. (1993). Alternative Ways of Assessing Model Fit. In K. A. Bollen, \& J. S. Long (Eds.), Testing Structural Equation Models (pp. 136-192). Newbury Park, CA: Sage.

Byrnes, J. P. (2008). Cognitive Development During Adolescence. In G.R. Adams \& M.D. Berzonsky (Eds.), Blackwell Handbook of Adolescence (pp. 227-246). Wiley-Blackwell.

Caparos, S., \& Blanchette, I. (2015). Affect et pensée logique : comment les émotions influencent notre raisonnement [Affect and logical thought: how emotions influence reasoning]. Revue québécoise de psychologie, 36(1), 57-70.

Channon, S., \& Baker, J. (1994). Reasoning strategies in depression: Effects of depressed mood on a syllogism task. Personality \& Individual Differences, 17(5), 707-711.

Chiesi, F., Gronchi, G., \& Primi, C. (2008). Age-trend-related differences in tasks involving conjunctive probabilistic reasoning. Canadian Journal of Experimental Psychology, 62(3), 188-191.

Cromer, J. A., Schembri, A. J., Harel, B. T., \& Maruff, P. (2015). The nature and rate of cognitive maturation from late childhood to adulthood. Frontiers in psychology, 6, 704. https://doi.org/10.3389/fpsyg.2015.00704

Csapó, B. (1997). The Development of inductive reasoning: Cross-sectional assessments in an educational context. International Journal of Behavioral Development, 20(4), 609-626.

Csikszentmihalyi, M., Abuhamdeh, S., \& Nakamura, J. (2005). Flow. In A. Elliot, \& C. Dweck (Eds.), Handbook of competence and motivation (pp. 598-608). New York: Guilford.

De Neys, W., \& Van Gelder, E. (2009). Logic and belief across the lifespan: the rise and fall of belief inhibition during syllogistic reasoning. Developmental Science, 12(1), 123-130.

Denison, S., Reed, C., \& Xu, F. (2013). The emergence of probabilistic reasoning in very young infants: Evidence from 4.5- and 6-month-olds. Developmental Psychology, 49(2), 243-249.

Fartoukh, M., Chanquoy, L., \& Piolat, A. (2014). Mood Induction in Children: Effect of the Affective Valence of a Text on Phonological Working Memory. Advances in Cognitive Psychology, 10(3), 113-118. doi:10.5709/acp-0162-z

Fiedler, K. (1990). Mood dependent selectivity in social cognition. European Review of Social Psychology, 1(1), 1-32.

Fonseca-Pedrero, E. (2018). Network analysis in psychology. Papeles Del Psicólogo, 39, 1-12. https://doi.org/10.23923/pap.psicol2018.2852 
Forgas, J. P. (1995). Mood and judgment: The affect infusion model (AIM). Psychological Bulletin, $117(1), 39-66$.

Galand, B., \& Philippot, P. (2005). L'école telle qu'ils la voient : validation d'une mesure des perceptions du contexte scolaire par les élèves du secondaire [School as they see it: Validation of a measure of secondary students' perceptions of the school context]. Canadian Journal of Behavioural science, 37(2), 138-154.

Galotti, K. M., Komatsu, L. K., \& Voelz, S. (1997). Children's differential performance on deductive and inductive syllogisms. Developmental Psychology, 33(1), 70-78.

Gana, K., \& Broc, G. (2018). Structural Equation Modeling with lavaan. England: ISTE Group.

Giroux, S-V., Blanchette, I., Gosselin, N. (2014). Influence des émotions sur le raisonnement logique - impact néfaste ou bienfait ?[Influence of Emotions on Logical Reasoning - Bad or Good Impactt?]. Poster presented at the 1ère Journée Scientifique du CogNAC, Trois-Rivière: Université du Québec, Quebec, Canada, October 2014.

Gosselin, J. \& Blanchette, I. (2018). L'influence des émotions intégrales positives sur le raisonnement déductif et inductif [The Impact Of Positive Integral Emotions On Deductive And Inductive Reasoning]. Revue québécoise de psychologie, 39, 245-268. https://doi.org/10.7202/1051230ar

Hawkins, J., Pea, R. D., Glick, J., \& Scribner, S. (1984). " Merds that laugh don't like mushrooms »: Evidence for deductive reasoning by preschoolers. Developmental Psychology, 20(4), 584-594.

Hevey, D. (2018). Network analysis: A brief overview and tutorial. Health Psychology and Behavioral Medicine, 6(1), 301-328. doi:10.1080/21642850.2018.1521283

Huntsinger, J. R., Isbell, L. M., \& Clore, G. L. (2014). The affective control of thought: Malleable, not fixed. Psychological Review, 121(4), 600-618.

JASP Team (2019). JASP (Version 0.11.1) [Computer software].

Keating, D. (2012). Cognitive and Brain Development in Adolescence. Enfance, 3(3), 267-279.

Kline, R. B. (2011). Principles and Practice of Structural Equation Modeling (3rd ed.). New York, NY: The Guilford Press.

MacCallum, R. C., Browne, M. W., \& Sugawara, H. M. (1996). Power analysis and determination of sample size for covariance structure modeling. Psychological methods, 1(2), 130-149.

Markovits, H., Schleifer, M., \& Fortier, L. (1989). Development of elementary deductive reasoning in young children. Developmental Psychology, 25(5), 787-793.

Melton, R. J. (1995). The role of positive affect in syllogism performance. Personality and Social Psychology Bulletin, 21(8), 788-794. https://doi.org/10.1177/0146167295218001

Mokhtarian, P. L., \& Ory, D. T. (2009). Structural Equations Models. In R. Kitchin, \& N. Thrift (Eds.), International Encyclopedia of Human Geography, Volume 11, (pp. 10-17). Oxford: Elsevier.

Nicholls, J. G., \& Thorkildsen, T. A. (Eds.) (1995). Reasons for learning: Expanding the conversation on student teacher collaboration. New York: Teachers College Press.

Oaksford, M., Morris, F., Grainger, B., \& Williams, J. M. G. (1996). Mood, reasoning, and central executive processes. Journal of Experimental Psychology: Learning, Memory, and Cognition, 22(2), 476-492. https://doi.org/10.1037/0278-7393.22.2.476

Radenhausen, R. A., \& Anker, J. M. (1988). Effects of depressed mood induction on reasoning performance. Perceptual and Motor Skills, 66(3), 855-860. https://doi.org/10.2466/pms.1988.66.3.855

Ricard-St-Aubin, J. S., Philippe, F. L., Beaulieu-Pelletier, G., \& Lecours, S. (2010). Validation francophone de l'Échelle des émotions différentielles IV (EED-IV) [French validation of the Differential Emotions Scale IV (DES-IV)]. Revue Européenne de Psychologie Appliquée/European Review of Applied Psychology, 60(1), 41-53.

Roalf, D. R., Gur, R. E., Ruparel, K., Calkins, M. E., Satterthwaite, T. D., Bilker, W. B., Hakonarson, H., Harris, L. J., \& Gur, R. C. (2014). Within-individual variability in neurocognitive performance: Age- and sex-related differences in children and youths from ages 8 to 21 . Neuropsychology, 28(4), 506-518. 
Royce, J. R., \& Diamond, S. R. (1980). A multifactor-system dynamics theory of emotion: Cognitive-affective interaction. Motivation and Emotion, 4(4), 263-298. https://doi.org/10.1007/BF00993581

Ryan, A. M., \& Patrick, H. (2001). The classroom social environment and changes in adolescents' motivation and engagement during middle school. American Educational Research Journal, 38(2), 437-460. doi: 10.3102/00028312038002437

Schwarz, N. (2012). Feelings-as-information theory. In P. Van Lange, A. W. Kruglanski, \& E. T. Higgins (Eds.), Handbook of theories of social psychology (Vol. 1, pp. 289-308). Thousand Oaks, CA: Sage.

Simon, W.E., \& Simon, M.G. (1975). Self-esteem, intelligence and standardized academic $\begin{array}{lllll}\text { achievement. Psychology in the Schools, 12(1), 97-100. } & \text {. }\end{array}$ https://doi.org/10.1002/1520-6807(197501)12:1<97::AID-PITS2310120119>3.0.CO;2-F

Steinberg, L. (2005). Cognitive and affective development in adolescence. Trends in Cognitive Sciences, 9(2), 69-74.

Tricard, E. (2018). Emotions et raisonnement : influence d'états émotionnels subjectifs sur les performances en raisonnement chez l'adolescent et le jeune adulte. [Emotions and reasoning: influence of subjective emotional states on reasoning performance in adolescents and young adults.] (Unpublished doctoral dissertation). Tours, Université de Tours, France.

Tricard, E., Maintenant, C., \& Pennequin, V. (2018). Effet de la valence émotionnelle induite sur le raisonnement déductif chez les enfants de 9-10 ans [Effect of the emotional valence induced on deductive reasoning in children of 9-10 years]. Neuropsychiatrie de l'enfance et de l'adolescence, 66(4), 203-209.

Valiente, C., Swanson, J., \& Eisenberg, N. (2012). Linking Students' Emotions and Academic Achievement: When and Why Emotions Matter. Child Development Perspectives, 6(2), 129-135. https://doi.org/10.1111/j.1750-8606.2011.00192.x

Wang, Y., Chen, J., \& Yue, Z. (2017). Positive Emotion Facilitates Cognitive Flexibility: An fMRI Study. Frontiers in Psychology, 8, 1-11. doi: 10.3389/fpsyg.2017.01832

\section{ACKNOWLEDGEMENTS}

This research is funded by the French National Research Agency (Agence Nationale de la Recherche): ANR-18-CE28-0004-01.

\section{AUTHORS' INFORMATION}

Full name: Sonya Yakimova

Institutional affiliation: Psychologie des âges de la vie et Adaptation (PAVeA) - EA 2114, Université de Tours, France

Institutional address: 3 rue des Tanneurs, BP 4103, 37041 TOURS Cedex 1

Short biographical sketch: Sonya Yakimova obtained her Ph.D. in Differential Psychology from Rennes 2 University and her M.A. in Social and Cognitive Psychology as well as her title of Social and I-O Psychologist from University of Nice Sophia Antipolis. She is interested in the application of Social and Differential Psychology in the fields of education, health and work. She is currently a Post Doc Researcher for the project „Psychological disengagement and self-esteem: a vicious cycle of Dropping out of school?" (DISESTEEM) at University of Tours and a member of the laboratory PAVeA- EA 2114. DISESTEEM is funded by a grant from the the French National Research Agency (Agence Nationale de la Recherche): ANR-18-CE28-0004-01. This project represents an international collaboration between University of Tours (France), University of Clermont Auvergne (France) and University of Moncton (Canada) with project manager Prof. Delphine Martinot.

Keywords: Dropping out of school, Orientation, Personality, Emotions, Self-esteem and self-efficacy, Quality of Life, Intergroup Relations. 
Full name: Célia Maintenant

Institutional affiliation: Psychologie des âges de la vie et Adaptation (PAVeA) - EA 2114, Université de Tours, France

Institutional address: 3 rue des Tanneurs, BP 4103, 37041 TOURS Cedex 1

Short biographical sketch: Célia Maintenant is a lecturer of developmental psychology at University of Tours and a full member of the laboratory PAVeA- EA 2114. She received her Ph.D. in developmental psychology at University of Provence (France). Her research focuses primarily on the study of the development of reasoning and emotions and their links, and the development of categorization and executive functions. Her current project is titled: „Psychological disengagement and self-esteem: a vicious cycle of Dropping out of school?“. This project is funded by a grant from the Agence Nationale de la Recherche (ANR). The general objective is to better understand how psychological disengagement operates as the first step of a process that may result in behavioral disengagement, that is, the act of dropping out of school.

Full name: Anne Taillandier-Schmitt

Institutional affiliation: Psychologie des âges de la vie et Adaptation (PAVeA) - EA 2114, Université de Tours, France; Cognition, Comportement et Communication (LP3C) -EA 1285, Université de Rennes 2, France.

Institutional address: 3 rue des Tanneurs, BP 4103, 37041 TOURS Cedex 1

Short biographical sketch: Anne Taillandier-Schmitt is a lecturer of social psychology at University of Tours and a full member of the laboratory PAVeA- EA 2114. Her research focuses on the relations between minority and majority groups. More specifically, on the relationship between immigrants and members of host societies. Another focus of his research is gender stereotypes. Her current project is titled: Psychological disengagement and self-esteem: a vicious cycle of Dropping out of school?" (ANR-18-CE28-0004-01) where she studies the effects of Organizational Citizenship Behaviors and their link with self-esteem. 